\title{
Simulating Arctic sea ice variability with a coupled regional atmosphere-ocean-sea ice model
}

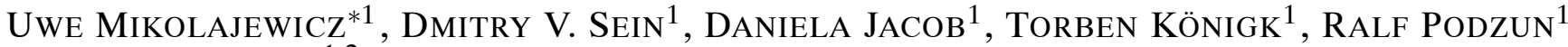 \\ and TIDO SEMMLER ${ }^{1,2}$
}

${ }^{1}$ Max-Planck-Institut für Meteorologie, Hamburg, Germany

${ }^{2}$ Present affiliation: C4I Met Éireann, Dublin, Ireland

(Manuscript received March 2, 2005; in revised form June 23, 2005; accepted September 9, 2005)

\begin{abstract}
A regionally coupled model consisting of the regional atmosphere model REMO and the global ocean model MPI-OM is forced with reanalysis data for the period 1958 to 2001. The coupled domain includes the Arctic Ocean, the Nordic Seas, the northern North Atlantic and Europe. The model simulates marked interannual variability in Arctic sea ice export through Fram Strait and reproduces the large event that lead to the Great Salinity Anomaly in the late 60s/early 70s. Ensemble simulations show large variability between different realisations indicating that a single realisation is not sufficient to analyse the climate response of the model to variations in the boundary conditions. With our experiments it is possible to show that both the largescale atmospheric circulation and the variability generated inside the model domain contribute to sea ice export events. In one of the ensemble members the sea ice export event in the mid 60s has led to permanent suppression of deep convection in the Labrador Sea up to the end of the experiment in 2001.
\end{abstract}

\section{Zusammenfassung}

Ein regional gekoppeltes Modell bestehend aus dem regionalen Atmosphärenmodell REMO und dem globalen Ozeanmodell MPI-OM wurde mit Reanalysedaten der Periode 1958 bis 2001 angetrieben. Das gekoppelte Modell umfasst die Arktis, das europäische Nordmeer, den nördlichen Nordatlantik und Europa. Der simulierte arktische Eisexport durch die Framstraße zeigt eine ausgeprägte interannuale Variabilität und das Modell reproduziert das Ereignis, das zu der sogenannten ,Großen Salzgehaltsanomalie‘ in den späten 60ern und frühen 70ern führte. Ensemblesimulationen zeigen eine ausgeprägte Variabilität zwischen den einzelnen Realisationen, was darauf hindeutet, dass eine einzelner Modellauf nicht ausreicht, um zuverlässig die Reaktion des Modells auf Signale in den Randbedingungen zu ermitteln. Unsere Experimente zeigen, dass sowohl Signale außerhalb des Modellgebiets als auch Variabilität, die ihren Ursprung innerhalb des Modellgebiets hat, wesentlich für die Variationen des arktischen Meereisexports sind. In einem Ensemblelauf führte das starke Eisexportereignis Mitte der 60er Jahre zu einer bis zum Ende des Experiments andauernden Unterdrückung der Tiefenkonvektion in der Labradorsee.

\section{Introduction}

The Arctic Ocean and the Nordic Seas are key regions for climate. This area shows a high sensitivity to climate change (e.g. anthropogenic greenhouse warming, see for an overview CUBASCH et al., 2001), furthermore deep water is formed here. As the essential processes (like e.g. sea ice formation/melting or deep convection) are strongly nonlinear, climate modelling in this region is rather challenging.

In spite of its importance for climate, this region is often poorly treated in almost all global climate models. The resolution of the ocean components is generally too coarse to resolve relevant oceanic processes like deep convection, overflows and ice edge processes. Most climate models so far have used strongly simplified sea ice components, often hampered by the assumption of an

\footnotetext{
*Corresponding author: Uwe Mikolajewicz, Max-Planck-Institut für Meteorologie, Bundesstrasse 53, 20146 Hamburg, Germany, e-mail: mikolajewicz@dkrz.de
}

artificial island on the North Pole to overcome the singularity of the widely used geographical coordinate system. Whereas this problem seems to be less severe in many of the currently applied climate models as a consequence of the option in some ocean models to shift the position of the poles onto land (and thus the singularity of the grid associated with them) by conformal mapping, resolution is still an issue. Here we present first results from an attempt to simulate Arctic climate variability on interannual time scales with a regionally coupled climate model. This layout allows a higher spatial resolution and thus better representation of many relevant processes in a key region of the ocean. Most studies of interannual sea ice variability have typically been performed with either stand-alone sea ice models (e.g. HILMER and LEMKE, 2000) or with ocean-sea ice models (e.g. HAAK et al., 2003) driven with data from reanalysis projects. Studies with coupled regional atmosphere-ocean-sea ice models have typically been integrated for only a few 
years (e.g. RINKE et al., 2003) and/or do not include a dynamic ocean (e.g. MASLANIK et al., 2000).

\section{The model}

The regionally coupled climate model consists of the regional atmosphere model REMO and the Max-PlanckInstitute for Meteorology ocean model (MPI-OM). The REgional atmosphere MOdel (REMO) is based on the 'Europa-Modell' of the German Weather service (MAJEWSKI, 1991). It can be alternatively used with the physical parameterisations of the German Weather Service or with the parameterisations of the global climate model ECHAM-4 (RoECKNER et al., 1996). The dynamical core of the model as well as the discretization in space and time are based on the 'Europa-Modell'. However, in REMO not enthalpy and total water content but temperature, water vapour and liquid water are prognostic variables (JACOB, 2001). The version of REMO applied in the present study has a partial formulation of land, water and sea ice in each grid cell (SEMMLER et al., 2004). The surface radiation, heat, moisture and momentum fluxes have to be calculated separately for each surface type. This is done according to AVISSAR and PiElKe (1989). A simple lake model with thermodynamic ice component has been added for the purpose of coupling. The version applied here has 19 levels in the vertical and a rotated spherical grid with a resolution of approx. $110 \mathrm{~km}$. The model domain includes the entire Arctic Ocean, the Nordic Seas and a large fraction of the North Atlantic (see Fig. 1).

The Max-Planck-Institute Ocean Model (MPI-OM, formerly C-HOPE, MAIER-REIMER, 1997; MARSLAND et al., 2002) is a primitive equation model (zlevel, with Boussinesq and incompressibility assumptions) formulated on an orthogonal curvilinear Arakawa C-grid. The model includes a dynamic-thermodynamic sea ice model with viscous-plastic rheology (HIBLER, 1979). It has a free surface and uses a mass flux boundary condition for salinity. A simple bottom boundary layer scheme is included as well as the standard set of sub-grid scale parameterisations (e.g. isopycnal diffusion, Richardson number dependent vertical diffusivities, a simple mixed layer scheme including the effect of wind mixing at the surface, and eddy induced tracer transport according to GENT et al., 1995).

The ocean model set up used in this study is formally global, but has high resolution in the Arctic, the Nordic Seas and the northern North Atlantic. This choice was made in order to have highest resolution in the regions relevant for deepwater formation and at the ice edge. The horizontal resolution gradually varies between a minimum of $15 \mathrm{~km}$ in the Arctic and a maximum of $300 \mathrm{~km}$ in the Southern Ocean (see Fig. 1). The model has 40 vertical levels with level thicknesses between 10 m near

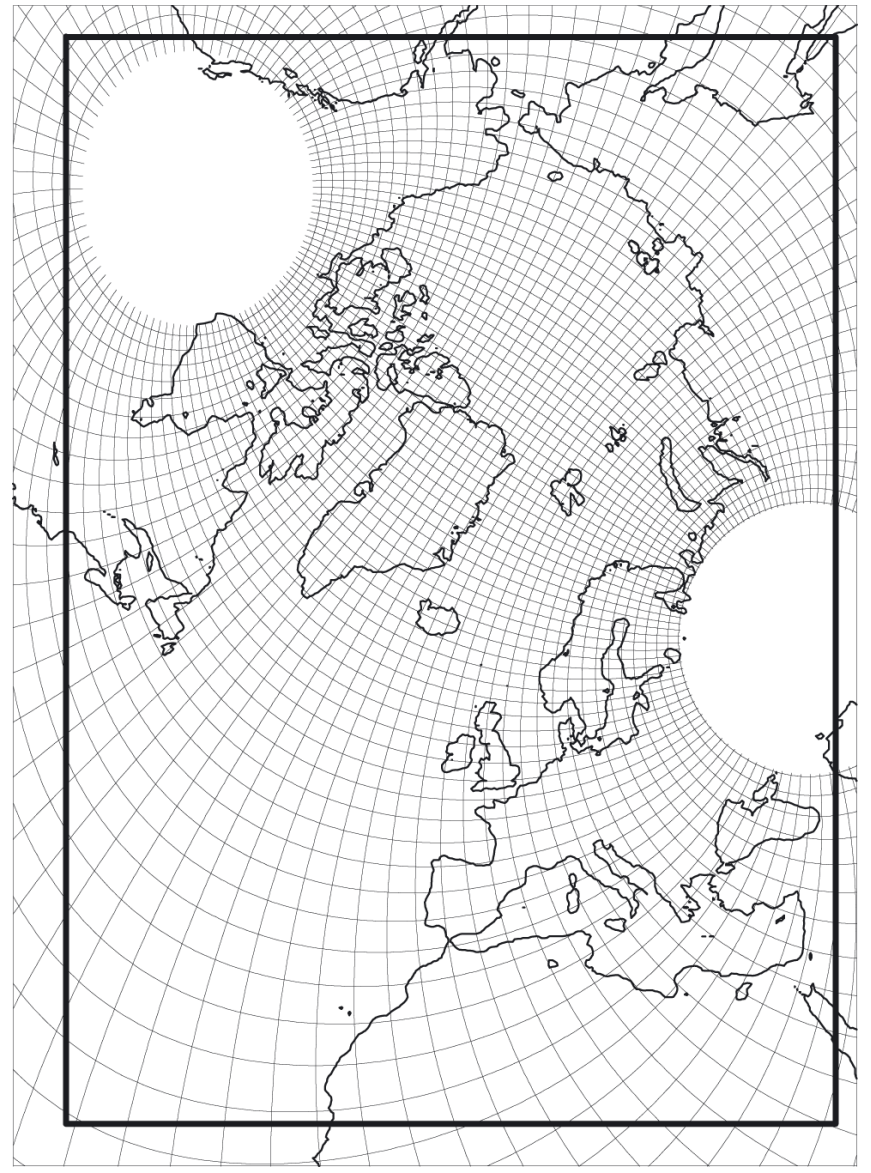

Figure 1: Grid configuration of the regionally coupled model. The thick black line indicates the domain of coupling. Only every forth line of the formally global ocean grid is shown. The atmosphere is defined on a regular grid within the domain bounded by the thick black line.

the surface and approx. $500 \mathrm{~m}$ in the deep abyssal plains. The upper $200 \mathrm{~m}$ of the water column is represented by 12 levels.

The coupling between the REMO atmosphere model and the MPI-OM ocean model was carried out using the OASIS coupler developed by CERFACS (VALCKE et al., 2000). REMO calculates fluxes of heat, momentum and freshwater (mass) separately for the sea ice covered and ice free fractions of a grid box and receives in turn SST and sea ice properties from the ocean model. The coupling is updated every 6 hours. A detailed description of the coupling procedure is given in SEIN et al. (2005).

In the area of our interest the ocean model has a much finer resolution than the atmospheric model. Thus the atmospheric fluxes are calculated on a much coarser grid and small scale sea surface temperature (SST) anomalies would not be damped adequately. To overcome this problem, a sub-grid-scale (with respect to the resolution of the atmosphere model) parameterisation of the heat fluxes over open water is used on the ocean grid. As the heat flux is strongly dependent on the SST, this correc- 
tion is assumed to be proportional to the difference between the SST calculated in the ocean model and the SST field on the scale of the atmospheric model resolution, which is obtained by interpolation of the SST onto the atmospheric grid and back. The proportionality constant, which is actually equal to $\mathrm{Q} / \mathrm{T}$, where $\mathrm{Q}$ is the net heat flux over open water and $\mathrm{T}$ is the sea surface temperature, was set according to RöSKE (2001) to $-30 \mathrm{~W} /\left(\mathrm{m}^{2} \mathrm{~K}\right)$. This value has been estimated using standard bulk formulas under the assumption that atmospheric variables do not change if the SST varies, which is certainly only appropriate for small scale SST anomalies.

As the atmosphere model is not global, additional forcing data are required at the lateral boundaries of the atmosphere. The global ocean model also requires surface forcing outside the domain covered by REMO. Here the fluxes from the atmosphere are calculated using the standard bulk formulas also used in the standalone ocean model (MARSLAND et al., 2002). The input data at the boundaries (lateral for the atmosphere as well as atmospheric input for bulk formulas outside the coupled domain) are taken from the NCEP/NCAR reanalysis (KALNAY et al., 1996) and updated every 6h. River runoff is calculated offline with a hydrological discharge model (HAGEMANN and DÜMENIL-GATES, 2001) using precipitation and temperature data from the NCEP reanalysis.

One general problem within regional coupled models is that on the global scale the freshwater balance is not closed as properties of the inflow into the model domain are calculated from the boundary conditions whereas the outflow properties are calculated from the actual state of the model. Also the prescribed river runoff is not necessarily consistent with the actual state of the atmospheric model.

\section{Spinup}

The ocean model has been started from climatological temperature and salinity (LEVITUS et al., 1998) and run repeatedly through the period 1948 to 2001, using forcing data from the NCEP reanalysis. Additionally to the calculated freshwater fluxes (prescribed precipitation and river runoff, and calculated evaporation) a salinity restoring in the surface layer $(0-12 \mathrm{~m})$ towards climatology with a time constant of 180 days is applied (corresponding to a restoring coefficient of 15 days $/ \mathrm{m}$ ). No salinity restoring is applied under sea ice. This procedure was repeated three times over the period 1948 to 2000 . The coupled model simulation was started from the last repeat cycle of the uncoupled ocean model (1.1.1958) and from NCEP reanalysis data for the atmosphere.

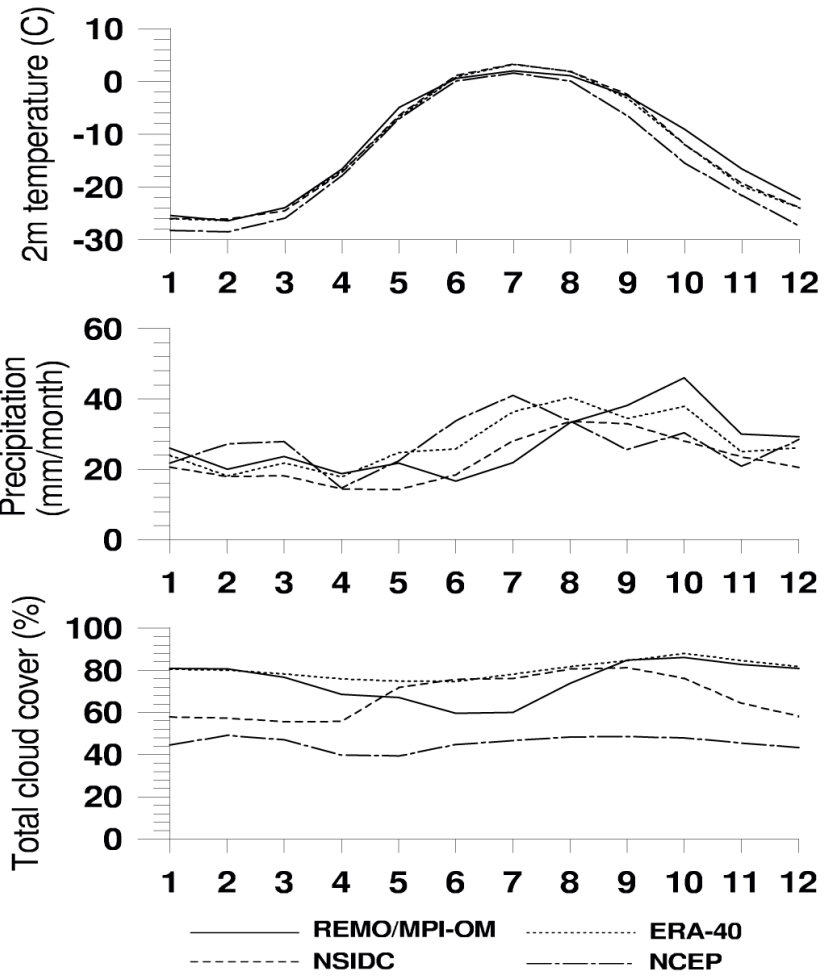

Figure 2: Seasonal cycle of surface air temperature (top), precipitation (middle) and total cloud cover (bottom) averaged over the Arctic north of $70^{2} \mathrm{~N}$. Data are shown for the present model, observations (NSIDC) and data from reanalysis projects (NCEP, ERA-40). For the model and the reanalysis data, all data are averages over the period 1959 to 1999. The NSIDC temperature data are averaged from 1981 to 1998 , the precipitation data from 1950 to 1999, and the cloud cover data from 1981 to 1990.

It turned out that the inconsistencies in the freshwater budget mentioned before were leading to a substantial drift of the model. To overcome this, in the first coupled integration (termed SPINUP in the following) salinity in the surface layer $(0-12 \mathrm{~m})$ was restored towards climatology in the ice free regions, with a time constant of 180 days. In subsequent experiments the restoring was switched off and instead a temporally constant freshwater flux correction was used calculated from the period 1972 to 2001 from the SPINUP integration. Heat and momentum fluxes are not adjusted.

\section{Climate of the model}

The model was integrated once more for the period 1958 to 2001 with NCEP boundary values using the state obtained at the end of the SPINUP integration at the 31.12.2001 as initial conditions for the year 1958. In the following the climate of this model simulation (termed CTR0) is compared to observations.

The seasonal cycle of various quantities averaged over the entire Arctic north of $70^{\circ} \mathrm{N}$ is shown in Fig. 2 for the model simulation CTR0, for two reanalysis data 
sets (NCAR/NCEP and ERA40, SIMMONS and GIBSON, 2000) and for observations (NSIDC 2000). With respect to near-surface air temperature the model simulates slightly too warm temperatures for most of the cold season. Typically this bias is smaller than $2 \mathrm{~K}$, but in October and November it is as large as $4 \mathrm{~K}$. Whereas the curves for NSIDC and ERA40 almost coincide, the NCAR/NCEP reanalysis is generally colder. The difference between the two reanalysis products has a similar magnitude as the difference between model and observations.

The seasonal cycle of cloudiness demonstrates a major problem in the atmospheric component. Whereas the observations reach a minimum below $60 \%$ total cloud cover in winter and a maximum of approximately $80 \%$ in summer, the simulated total cloud cover shows a reversed signal: A minimum in summer and a maximum in winter, thus explaining the too warm surface temperatures over the Arctic in the model. The underestimation of the cloud cover in summer is consistent with an overestimation of the summer mean sea level pressure of roughly $4 \mathrm{hPa}$ (not shown). The two reanalysis products, however, show no seasonal cycle in cloudiness at all, with NCAR/NCEP cloud covers below $50 \%$ and ERA40 around $80 \%$. However, it should be mentioned that the model derived total cloud covers are a diagnostic quantity estimated from the simulated three-dimensional distribution of clouds. The simulated precipitation is generally slightly overestimated, but in the annual mean comparable to ERA40 and NCEP. The model has a trend to underestimate summer precipitation (slight in comparison with observations, strong in comparison to the reanalysis products), which is consistent with the too high summer pressure and the underestimated cloudiness. In fall the model produces too much precipitation. In October the simulated precipitation reaches a clear maximum, whereas the other data sets show their maximum in July or August.

The simulated climatological sea ice distribution averaged over the period 1978 to 2000 is shown in Fig. 3 together with a climatology derived from satellite observations from the same period (COMISO, 1998). In winter the agreement between modelled ice edge and observed ice edge is quite good. The main exception is 'Is odden', which in the model appears quite seldom and does not extend far enough into the Greenland Sea. Tests indicate that this improves largely if a higher resolution ocean model is used. The melting at the coast of the Labrador Sea is overestimated and the ice edge does hardly reach Newfoundland.

The simulated sea ice thickness is shown in Fig. 4a and $b$. In wintertime the simulated ice thickness in the central Arctic lies between 3 and $3.5 \mathrm{~m}$, in summer between 2 and $2.5 \mathrm{~m}$. Compared to the climatology from
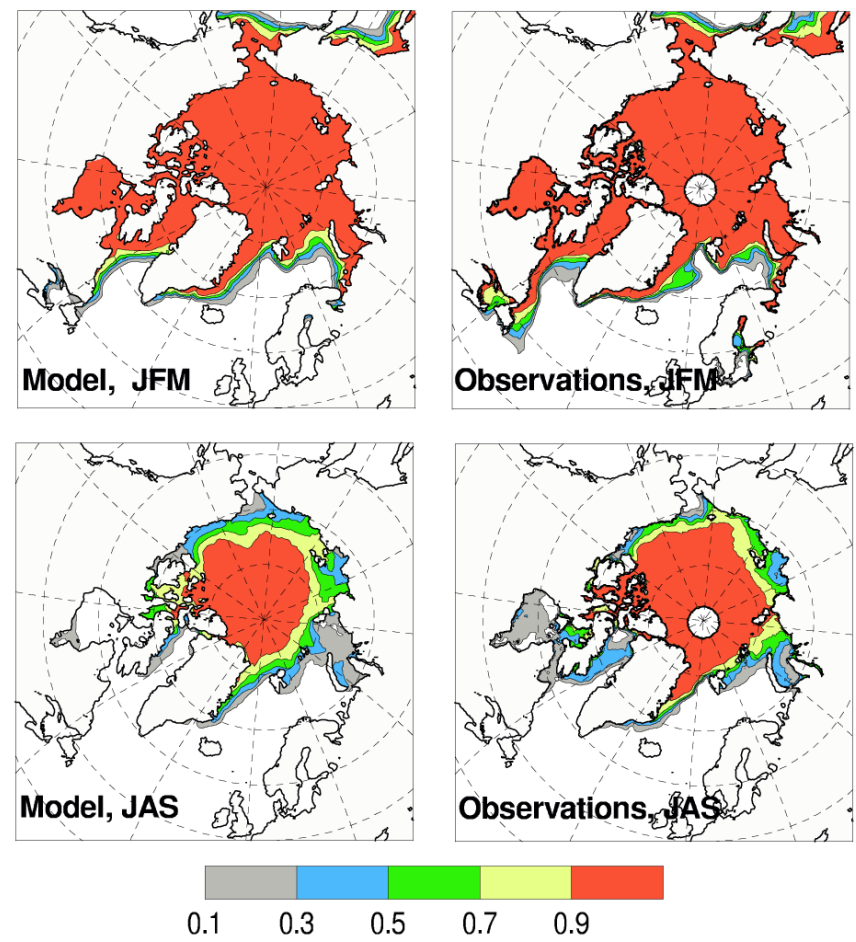

Figure 3: Probability of presence of sea ice for winter (JFM, top) and summer (JAS, bottom) both for the present model (left) and estimates derived from SSMI/SSMR data (COMISO, 1998) (right). Both data sets cover the period 1978 to 2000 . Presence of sea ice is defined as a sea ice concentration larger than $15 \%$.

(BOURKE and GARRETT, 1987) the model systematically underestimates the sea ice thickness especially near Greenland and in the Beaufort Sea. However, comparison of the model results with satellite derived estimates of winter sea ice thickness (LAXON et al., 2003) reveals an overestimation of sea ice thickness in the Beaufort Sea and an underestimation in the Atlantic sector of the Arctic (for years 1994 to 2001, not shown). In summer the model overestimates sea ice melting. The underestimation of the cloud cover in spring and summer and the resulting overestimation of downward short wave radiation strongly contributes to this effect in the central Arctic. The melting starts too early and surface temperatures in spring are too warm. As a consequence the ice edge retreats too far and the simulated sea ice concentration is typically only $70 \%$ and the simulated sea ice thickness is too thin.

The model forms deepwater both in the Greenland Sea and the Labrador Sea by open ocean convection. The simulated northward ocean heat transport in the Atlantic compares well with observations. It reaches a maximum of slightly more than $1 \mathrm{PW}$ south of $30^{\circ} \mathrm{N}$ (outside the coupled domain). At $50^{\circ} \mathrm{N}$ (entirely in the coupled domain) the northward heat transport is a bit higher than $0.5 \mathrm{PW}$. The maximum strength of the overturning cell associated with North Atlantic deep water (NADW) is 


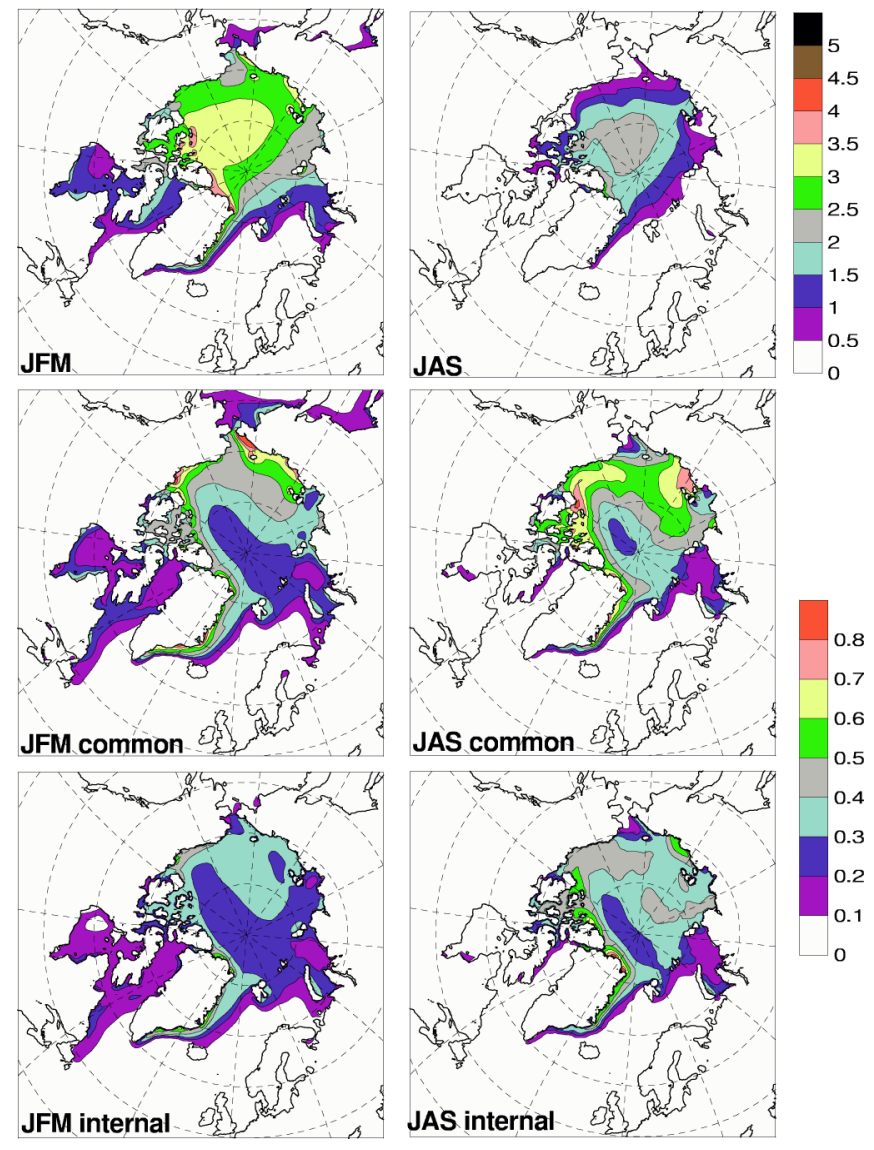

Figure 4: The top panels show modelled mean sea ice thickness for winter (JFM, left) and summer JAS, right). The other panels show the standard deviation of 'common' (middle) and 'internal' (bottom) variability for sea ice thickness in winter (left) and summer (right). 'Common' variability refers to the variability of the ensemble mean, 'internal' variability to the deviations from this. Sea ice thickness $[\mathrm{m}]$ is defined as average thickness within an ocean box and is given in $\mathrm{m}$.

approximately $19 \mathrm{~Sv}$ at $36^{\circ} \mathrm{N}$, close to the margin of the coupled domain. The model basically reproduces the meridional overturning circulation of the Atlantic (for an overview see e.g. Gordon, 1986 or Schmitz, 1995). A detailed validation is presented by SEIN et al., 2005.

\section{Ensemble simulations}

As the model domain is relatively large for a regional model, we considered it worth wile to perform ensemble integrations. Three additional experiments were performed. They differed from the original simulation CTR0 in the fact that the atmospheric $\mathrm{CO}_{2}$ concentration was increased by $1 \mathrm{ppm}$ for the first one, two or three months of the experiments. These experiments will in the following be termed CTR1, CTR2 and CTR3. After this initial perturbation, all experiments are run with exactly the same model parameters and exactly the same boundary values. A few time series of integral quantities of the model are shown in Fig. 5.

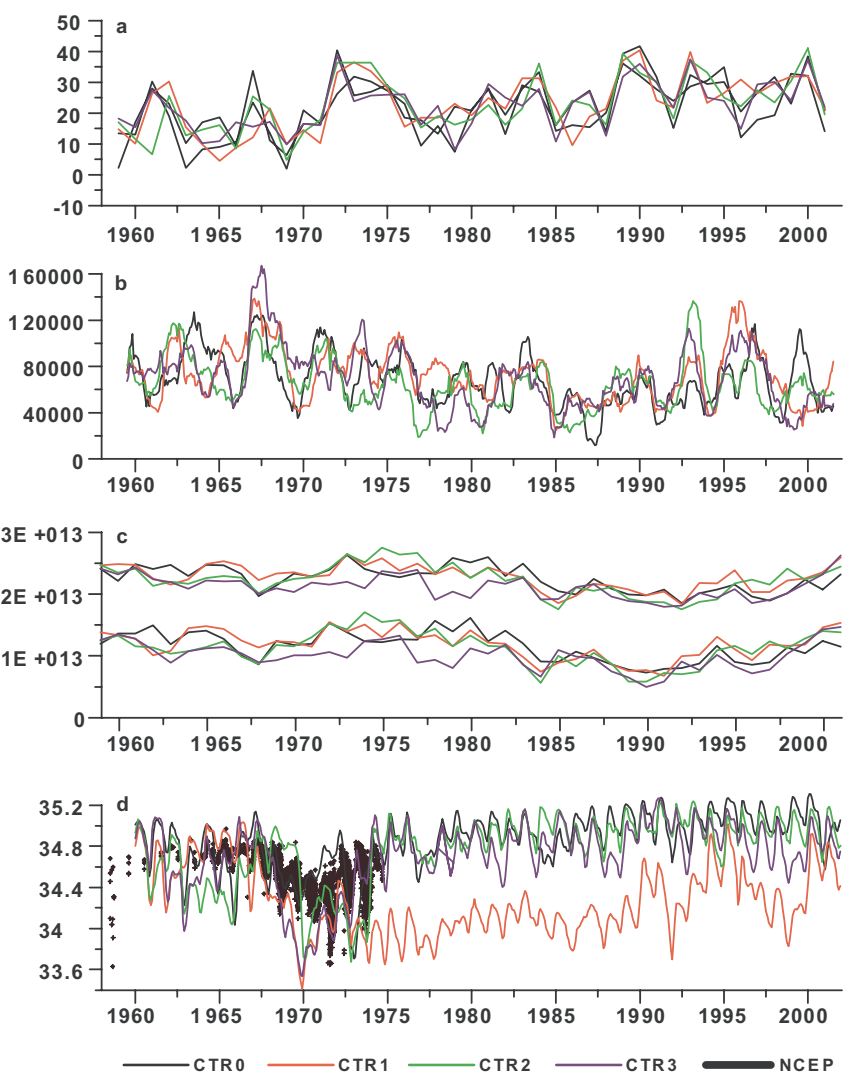

Figure 5: Time series of selected model quantities from ensemble simulation, from top to bottom: a) Winter sea level pressure difference (DJF) between Azores and Reykjavik together with values from the NCEP reanalysis in hPa. b) Arctic sea ice export through Fram Strait (12 month running mean) in $\mathrm{m}^{3} / \mathrm{s}$. c) Ice volume in the Arctic Ocean (excl. the Barents, the Kara and the Nordic Seas in $\mathrm{m}^{3}$ for summer (JAS, lower values) and winter (JFM). d) Salinity in the central Labrador Sea averaged over the depth interval from 20 to 60 $\mathrm{m}$ together with observations (crosses) in permille.

The simulated gradient in winter (DJF) mean sea level pressure between the Azores and Reykjavik is shown in Fig. 5a together with the data from NCEP reanalysis. All curves show a rather similar behaviour through time. The different members of the ensemble show some spread, but in general the spread is smaller than the common signal. This is a clear hint that the modelled NAO variability is to a large degree determined by the boundary conditions and thus the large scale atmospheric circulation. In a statistical sense this can be seen from the fact, that the variance of the time variations of the ensemble mean is almost four times as large as the variance of the deviations of the individual members of the ensemble from this mean. The model reproduces the observed NAO variability quite well. The variance of the differences between individual members of the ensemble and the NCEP derived NAO lies within the range given by the differences between two different ensemble members, although there is a slight tendency to relative high values. 
The time evolution of the sea ice export from the Arctic through Fram Strait shows a marked interannual variability. The mean value of the model is approx. 68000 $\mathrm{m}^{3} / \mathrm{s}$ sea ice. This value is approx. $20 \%$ smaller than the size of this quantity estimated from observations $\left(88000 \mathrm{~m}^{3} / \mathrm{s}\right.$ from AAGARD and CARMACK 1989 and $81000 \mathrm{~m}^{3} / \mathrm{s}$ from VINJE, 2001), but lies within the error bars of the estimates. The model shows a marked sea ice export event in the winters of 1966/67 and 1967/68 (see Fig. 5b). This export event is obvious in all ensemble members. In this time span sea ice export is almost doubled compared to the model's climatology. Single ensemble members also show huge sea ice export events in 1993 and 1997. However, other ensemble members show quite normal rates of sea ice export in these years. From the time series it becomes obvious, that the large scale atmospheric circulation seems to set the stage for large sea ice export events, but that the strength of the event itself is strongly determined by regional climate fluctuations. The common variance is approximately twice as large as the variance between the ensemble members, indicating the dominance of the forcing from outside the model domain. A detailed analysis shows that all export events are accompanied (and most likely caused, judged from uncoupled sensitivity experiments see e.g. HAAK et al., 2003) by anomalous northerly winds over Fram Strait. Time series of the pressure gradient across Fram Strait (not shown) thus are highly correlated with the sea ice export. The strong sea ice export event leading to the GSA is accompanied by a reduction in Arctic ice volume (see Fig. 5c). On top of the interannual variability the sea ice volume in the Arctic Ocean shows a marked decadal variability with a strong minimum between the late 80 s and early 90 s. This decadal variability is quite different from the typical variability found in models driven with NCEP reanalysis data which show a typical 'hat structure' (e.g. HILMER and LEMKE, 2000; HAAK et al., 2003): A minimum in the $50 \mathrm{~s}$ is followed by a period of high sea ice volumes before the huge ice export event leading to the GSA and a second maximum in the late 80 s with a subsequent decrease in sea ice volume till year 2000 . Whereas the uncoupled model does show this behaviour - except for the different spatial resolution it is the same model as the one applied in HAAK et al. (2003) - the coupling obviously leads to different decadal variability of heat and freshwater fluxes.

Enhanced sea ice export through Fram Strait leads to enhanced freshwater supply into the East Greenland Current and a substantial fraction of this anomaly is advected around the southern tip of Greenland into the Labrador Sea. The result is a freshening of the surface waters in the Labrador Sea. The lower surface density leads to reduced convection and thus mixing with the underlying warmer and saltier water masses. This feedback amplifies the negative salinity anomaly further and prolongs its persistence. The simulated near surface salinity averaged over a box in the central Labrador Sea is shown in a Fig. 5d together with observations (most of them have been measured from the ocean weathership Bravo). After the simulated big ice export event in the late sixties the surface salinity is reduced substantially and resembles the 'Great salinity anomaly' (GSA) described in detail by DICKSON et al. 1988. The results of the present coupled model are consistent with the mechanism described in HAAK et al. (2003) in an uncoupled ocean model driven by NCEP forcing. Whereas three ensemble members show - similarly to the observations - a return to normal conditions in the Labrador Sea, the behaviour of experiment CTR1 shows that the model now operates on a different mode of convection patterns. At least for the last 25 years of this experiment CTR1 shows strongly reduced convective activity in the Labrador Sea. As a consequence the model simulates in wintertime both colder surface temperatures as well as extended sea ice cover in the Labrador Sea. It is at first sight surprising that the export event in this simulation is not the strongest event (see Fig. 5b). However, calculating the net export of freshwater further south through Denmark Strait (relative to a reference salinity of 34.8), this experiment shows the strongest values (peaking with more than $130.000 \mathrm{~m}^{3} / \mathrm{s}$ in the levels above the isopycnal 27.0 in the winter of $1968 / 1969$ - mostly due to sea ice - compared to a climatological model mean of 48,000 $\mathrm{m}^{3} / \mathrm{s}$, not shown) with consistently high export values also in the previous three years. The time series of NAO indices reveal (see Fig. 5a) that the modelled NAO index in this run is either the lowest $(63 / 64,65 / 66$ and 66/67) or the second lowest (62/63 and 64/65) of the ensemble. A relatively low NAO index indicates relatively warm and mild conditions in the Labrador Sea with weak convection. Therefore the convection in the Labrador Sea is for several years lower than in the other runs. As a result a relatively stable stratification develops in the years previous to the arrival of the sea ice export signal. The combined magnitude of these two effects reducing surface salinity is sufficient to bring the model across a bifurcation threshold, and deep convection is suppressed for the remaining three decades of this model simulation. The variations in the Arctic freshwater export through the Canadian Archipelago are substantially smaller and do not seem to contribute substantially to the variations in Labrador Sea convection. In experiment CTR1 this transport is relatively weak compared to the other experiments, which can be explained by the reduced sea level gradient between the Arctic and the Labrador Sea 
caused by the reduced density in the Labrador Sea and by weaker northerly winds. The atmospheric freshwater flux (precipitation and evaporation) and the prescribed river runoff show a positive anomaly in all experiments for the years 1969 and 1970 of about $10000 \mathrm{~m}^{3} / \mathrm{s}$. The anomaly is strongest in run CTR1.

The total amount of anomalous freshwater input into the Labrador Sea (via Denmark Strait, the Canadian archipelago and by anomalous surface fluxes) amounts to roughly $2500 \mathrm{~km}^{3}$, a rather similar size compared to the anomalous freshwater content given for the GSA in literature (DICKSON et al., 1988).

The ensemble simulations allow to discriminate between variability generated inside the model domain and the variance caused by the large scale atmospheric flow. The latter, induced by the boundary conditions, is common to all experiments whereas the former is - except for the first years - independent for all experiments. An estimate can be derived by calculating the temporal variance of the ensemble mean for each grid point (termed 'common variance' in the following) and also for the deviations from the ensemble mean ('internal variance' in the following). Together these two quantities add up to the total variance. It should be noted that the relatively small size of the ensemble (4) leads to a systematic underestimation of the internal variability. The associated standard deviations for sea ice thickness are shown in Fig. 4. In winter the large scale atmospheric flow determines the general drift pattern of Arctic sea ice. Consequently the variability is largest where thick sea ice is piled up by the wind against topography or is driven away from it. Thus north of Greenland, Canada end eastern Siberia maxima of common variability of more than $0.6 \mathrm{~m}$ (standard deviation) can be seen. In the central Arctic the common variability is typically smaller by a factor 2 . The model domain generated variability shows weaker gradients in the Arctic. Whereas in the central Arctic its contribution to the total variance reaches almost $50 \%$ it is close to $20 \%$ at the coasts. Sea ice variability in the Pacific is in our model entirely caused by the boundary conditions, not a real surprise given the proximity to the boundary of the model domain. The variability in the East Greenland Current is relatively high, caused by the large variations in Arctic sea ice export through Fram Strait. In summer the spatial patterns of both kinds of variability are similar as in winter, but the relative contribution of variability generated inside the model domain is generally larger.

\section{Summary and conclusions}

Our multidecadal ensemble simulations show considerable variations in the simulated climate signals between the individual members. Whereas the need for ensemble simulations for synoptic variability was known before (e.g. WEISSE et al., 2000), the results of our study emphasizes also the need of ensemble simulations for interannual variability. However, the importance to use ensemble simulations must be expected to increase with the size of the model domain and is likely to depend on the region. One of the ensemble members obviously passed a bifurcation point in the late 60 s with suppressed deep convection in the Labrador Sea for the next three decades. It behaves similar to experiments where the effect of melt water input into the Labrador Sea was studied (e.g. MAIER-REIMER and MiKOLAJEWICZ, 1989 or SCHILlER et al., 1997). Towards the end of the simulation there are some hints for enhanced convective activity, but it is not clear whether this is an indication that the model would return to normal convective activity in case the simulation would be continued. In principle this type of bifurcation points is well known from the studies dealing with the stability of the thermohaline circulation, however it is not clear, how close the real climate system is to these bifurcation points. The ensemble is far too small to allow firm estimates of the likelihood of crossing the bifurcation point in the model. It should be mentioned as well that at least some feedback mechanisms involving changes in the large-scale atmospheric flow in response to a reduced thermohaline circulation are suppressed, this might have affected the stability of the system against perturbations. This aspect will certainly require further investigations.

\section{Acknowledgements}

This work was supported by the Deutsche Forschungsgemeinschaft through the Sonderforschungsbereich 512 and to a smaller part by the EU funded project AICSEX. The comments of Ernst MAIER-REIMER and Jens MEINCKE helped to improve the manuscript. We thank ECMWF for supplying the reanalysis data used for model verification.

\section{References}

AagaARD, K., E. CARMACK, 1989: The role of sea ice and other freshwater in the Arctic circulation. - J. Geophys. Res. 94, 14,485-14,498.

Avissar, R., R. A. Pielke, 1989: A parameterization of heterogeneous land surfaces for atmospheric numerical models and its impact on regional meteorology. - Monthly Weather Review 117, 2113-2136.

BOURKE, R. H., R. P. GARRETT , 1987: Sea ice distribution in the Arctic ocean. Cold Reg. - Sci Technol. 13, 259-280.

Comiso, J., 1999, updated 2002: Bootstrap sea ice concentrations from Nimbus-7 SMMR and DMSP SSM/I. - Boulder CO, USA: National Snow and Ice Data Center, Digital media. 
Cubasch, U., G. A. Meehl, G. J. Boer, R. J. StoufFer, M. Dix, A. NodA, C. A. Senior, S. Raper, K. S. YAP, 2001: Projections of Future Climate Change. In: Climate Change 2001: The Scientific Basis. Contribution of the Working Group 1 to the Third Assessment Report of the Intergovernmental Panel on Climate Change. Ed. by Houghton, J. T., Y. Ding, D .J. Griggs, M. Noguer, P. J. VAn Der Linden, X. DAi, K. MASKell, C. A. Johnson. Cambridge University Press, Cambridge, United Kingdom and New York, NY, USA, 881 pp.

Dickson, R. R., J. Meincke, S.-A. Malmberg, A. J. LEE, 1988: The Great Salinity Anomaly in the North Atlantic. - Nature 256(5517), 479-482.

Gent, P. R., J. Willebrand , T. MCDougall T., J. C. MCWILliams, 1995: Parameterizing eddy-induced tracer transports in ocean circulation models. - J. Phys. Oceanogr. 25, 463-474.

GORDON, A. L., 1986: Interocean exchange of thermocline waters. - J. Geophys. Res. 91, 5037-5046.

HAAK, H., J. JungClaus, U. MikolajewiCZ, M. LATIF, 2003: Formation and propagation of great salinity anomalies. - Geophys. Res. Lett. 30 (9); DOI: 10.1029/2003GL017065.

HAGEDORN, R., A. LEHMANN, D. JACOB, 2000: A coupled high resolution atmosphere-ocean model for the Baltex region. - Meteorol. Z. 9, 7-20.

Hagemann, S., L. DüMenil-Gates, 2001: Validation of the hydrological cycle of ECMWF and NCEP reanalyses using the MPI hydrological discharge model. - J. Geophys. Res. 106, 1503-1510.

HIBLE R, W. D., 1979: A dynamic thermodynamic sea ice model. - J. Phys. Oceanogr. 9, 815-846.

Hilmer, M., P. LEMKE, 2000: On the decrease of Arctic sea ice volume. - Geophys. Res. Lett. 27, 3751-3754.

JACOB, D., 2001: A note to the simulation of the annual and interannual variability of the water budget over the Baltic Sea drainage basin. - Meteorology and Atmospheric Physics 77, 1-4, 61-73.

KALNAY, E., and 22 co-authors, 1996: The NCEP/NCAR 40Year reanalysis project. - Bull. Amer. Meteor. Soc. 77(3), 437-470.

LAXON, S., N. PEACOCK, D. SMITH., 2003: High interannual variability of sea ice thickness in the Arctic region. Nature 425, 947-950.

Levitus S., T. P. Boyer, M. E. Conkright, T. O’Brien, J. Antonov, C. Stephens, L. Stathoplos, D. Johnson, R. GElfEld, 1998: World Ocean Database 1998: Volume 1: Introduction. - NOAA Atlas NESDIS 18, Ocean Climate Laboratory, National Oceanographic Data Center, U.S. Gov. Printing Office, Wash., D.C.

MAIER-REIMER, E., 1997: Design of a closed boundary regional model of the Arctic Ocean. - Bull. Amer. Meteor. Soc.: Workshop on polar processes in global climate 13-15 Nov, 1996, 72-73.

MAIER-REIMER, E., U. MiKolajewiCZ, 1989: Experiments with an OGCM on the cause of the Younger Dryas. - In: A. Ayala-Castanares, W. Wooster, A. YAÑEZ-ARANCIBA, (Eds.): Oceanography 1988, 87-100. - UNAM Press. Mexico D.F, 207 pp.

MAJEWSKI, D., 1991: The Europa Modell of the Deutscher Wetterdienst. - Seminar Proceedings ECMWF, ECMWF,
Shinfield Park, Reading, Berks, United Kingdom, 2, 147191.

Marsland, S. J., H. HAAK, J. H. Jungclaus, M. LATIF, F. RÖSKE, 2002: The Max-Planck-Institute global ocean/sea ice model with orthogonal curvilinear coordinates. - Ocean Modelling 5(2), 91-127.

Maslanik, J. A., A. H. LynCh, M. C. Serreze, W. Wu, 2000: A case study of regional climate anomalies in the Arctic: Performance requirements for a coupled model. J. Climate 13, 383-401.

NSIDC, 2000: The Arctic Climatology Project - Arctic Meteorology and Climate Atlas. - CD-ROM available at nsidc@kryos.colorado.edu, NSIDC, University of Colorado at Boulder.

Rinke, A., R. Gerdes, K. Dethloff, T. KandlBINDER, M. KARCHER, F. KAUKER, S. FricKenHaus, C. Köberle, W. Hiller, 2003: A case study of the anomalous Arctic sea ice conditions during 1990: Insights from coupled and uncoupled regional climate model simulations. - J. Geophys. Res. 108, 4275, DOI:10.1029/2002JD003146.

RoECKNER, E., K. ARPE, L. Bengtsson, M. Christoph, M. Claussen, L. Dümenil, M. Esch, M. Giorgetta, U. Schlese, U. SchulzWeidA, 1996: The Atmospheric General Circulation Model ECHAM-4: Model Description and Simulation of Present-Day- Climate. - Max-Planck-Institut für Meteorologie, Hamburg, Report No. 218.

Röske, F., 2001: An atlas of surface fluxes based on the ECMWF re-analysis - a climatological dataset to force global ocean general circulation models. - Max-PlanckInstitut für Meteorologie, Hamburg, Report No. 323, 31 pp.

Schiller, A., U. Mikolajewicz, R. Voss, 1997: The stability of the North Atlantic thermohaline circulation in a coupled ocean-atmosphere general circulation model. Climate Dynamics 13, 325-347.

SCHMITZ, W. J., 1995: On the interbasin-scale thermohaline circulation. - Rev. Geophys. 33, 151-173.

Sein, D. V., U. MikolajeWiCZ, D. JACOB, T.Semmler, R. PodzUN, 2005: Part I: A coupled regional climate model. Model description and validation. - Climate Dynamics, submitted.

Semmler, T., D. Jacob, K. H. Schlünzen, R. Podzun, 2004: Influence of sea ice treatment in a regional climate model on boundary layer values in the Fram Strait region. - Monthly Weather Review 132(4), 985-999.

Simmons, A. J., J. K. GiBSON, 2000: The ERA-40 Project Plan. - ERA-40 Project Report Series 1, ECMWF, Shinfield Park, Reading, UK, 63 pp.

Valcke, S., L. Terray, A. Piacentini, 2000: The OASIS Couplet User's Guide, Version 2.4. - Tech. Rep. TR/CGMC/00-10, CERFACS, 85 pp.

VINJE, T., 2001: Fram Strait ice fluxes and atmospheric circulation: 1950-2000. - J. Climate 14, 3508-3517.

Weisse, R., H. HEYEN, H. VON STORCH, 2000: Estimating the uncertainty in a regional climate model related to initial and lateral boundary conditions. - Mon. Weather Review 128, 3631-3642. 